This is an author produced version of a paper published in Peptides. This paper has been peer-reviewed but does not include the final publisher proof-corrections or journal pagination.

Citation for the published paper:

Wierup N, Sundler F.

"CART is a novel islet regulatory peptide"

Peptides, 2006, Vol: 27, Issue: 8, pp. 2031-6.

http://dx.doi.org/10.1016/j.peptides.2006.02.011

Access to the published version may require journal subscription.

Published with permission from: Elsevier 


\section{CART is a novel islet regulatory peptide.}

Nils Wierup and Frank Sundler

Department of Experimental Medical Science, Division of Diabetes, Metabolism, and

Endocrinology, Lund University, Lund, Sweden.

Corresponding author:

Nils Wierup, PhD

Lund University

Department of Experimental Medical Science

Division of Diabetes, Metabolism, and Endocrinology

Unit of Neuroendocrine Cell Biology

BMC F10

22 184, Lund

Sweden

Phone: +46462223630

Fax: +46462224546

e-mail: nils.wierup@med.lu.se 


\section{ABSTRACT}

CART peptides have emerged as important islet regulators. CART is expressed both in islet endocrine cells and in parasympathetic and sensory nerves innervating the islets. In adult rats the intra-islet expression of CART is limited to the somatostatin producing $\delta$-cells, while in adult mice CART is mainly expressed in nerve fibers. During development islet CART is upregulated; in rats in almost all types of islet endocrine cells, including the insulin producing $\beta$-cells, and in mice mainly in the $\alpha$-cells. This pattern of expression peaks around birth. CART is also expressed in human pancreatic nerves and in islet tumours where the expression level of CART may be related to the degree differentiation of the tumour. Interestingly, in several rat models of type 2 diabetes CART expression is robustly upregulated in the $\beta$-cells, and is prominent during the phase of beta cell proliferation and hypertrophy. While CART inhibits glucose stimulated insulin secretion from rat islets it augments insulin secretion amplified by cAMP. Mice lacking CART, on the other hand, have islet dysfunction, and humans with a missense mutation in the cart gene are prone to develop type 2 diabetes. These data favour a role of CART in normal islet function and in the pathophysiology of type 2 diabetes. 


\section{INTRODUCTION}

The pancreatic islets contain four main cell types; insulin-producing $\beta$-cells, glucagonproducing $\alpha$-cells, somatostatin-producing $\delta$-cells and pancreatic polypeptide (PP) producing PP-cells. Recently a fifth islet cell type, the ghrelin cell, was identified in human and rodent islets [34; 36]. Further, gastrin producing cells are present in the developing rat islets [22]. In addition to the peptides expressed in "own” cell types a great number of regulatory peptides are more promiscuously expressed in the developing islets and coexist with the established hormones, some of them transiently during development and/or when the islets are challenged, e.g. in type-2 diabetes. Such co-expressed peptides in islet cells include neuropeptide Y (NPY), peptide YY (PYY), islet amyloid polypeptide (IAPP), and calcitonin gene-related peptide (CGRP) which have been reviewed elsewhere [25]. Many of these peptides are also present in nerves innervating the pancreas [reviewed in 1].

Expression of CART in endocrine cells has been reported in other organs, including pituitary [7; 9], adrenal medulla [7; 11; 20], and in the antral gastrin producing G-cells in the stomach [12]. Here we review the distribution of CART in the pancreas and functional islet related data obtained so far. Special attention has been given to the distribution pattern of CART in the islets and to the role of CART in islet function.

\section{CART distribution and expression in the pancreas.}

Fetal, neonatal and adult rodent islet cells.

In normal adult rats CART is mainly expressed in the somatostatin producing $\delta$-cells and in pancreatic neurons [18; 35]. However, during development CART is highly expressed also in $\beta$-cells (Fig. 1), $\alpha$-cells, PP-cells, but somewhat surprisingly, not in the ghrelin cells [35]. In the rat, islet ghrelin cells deviate from the other islet cells in that they are only present during 
fetal and neonatal development and virtually disappear a few weeks after birth [36]. A similar developmental pattern holds also for the gastrin producing islet cells, but in contrast to the ghrelin cells a great proportion of the gastrin producing cells express CART [22; 35]. The expression of CART in the islet gastrin cells is reminiscent of the CART expression in the gastric G-cells of adult rats [12]. In adult mouse islets only very few $\delta$-cells are weakly CART IR [38]. However in developing mouse islets CART is upregulated in the $\alpha$-cells (Fig 2C). In contrast to the developing rat islets, virtually no CART immunoreactive (IR) $\beta$-cells (Fig 2AB), and no CART IR $\delta$-cells (Fig 2B and D) were detected. In addition, a small subpopulation of the PP-cells and the ghrelin cells were CART IR.

\section{Islets of rodent models of type-2 diabetes}

CART is markedly upregulated in the $\beta$-cells of several type- 2 diabetes models of rats and mice. One such model is dexamethasone (DEX) induced diabetes [30]. Rats treated with DEX in a high dose for 12 days display ten-fold higher relative number of CART IR $\beta$-cells (Fig 3) and ten-fold higher CART mRNA expression compared to control rats [39]. The GK rat, a polygenic model of inherited type-2 diabetes [14], displays thirty-fold higher relative number of CART IR $\beta$-cells paralleled by a robust increase in CART mRNA expression compared to the Wistar control rats [39]. CART is robustly upregulated also in the $\beta$-cells of ob/ob mice, and Zucker Diabetic Fatty (ZDF) rats [37]. Altogether, CART is upregulated in the $\beta$-cells of four, mechanistically different, models of typ-2 diabetes in two different species. Interestingly, in the CNS CART is positively regulated by leptin, and leptin deficient animals have decreased expression of CART in the CNS [13; 21]. Our finding of increased expression of $\beta$-cell CART in ZDF rats and ob/ob mice, which have disrupted leptin signalling, are therefore somewhat surprising and quite opposite of the central effect. To our knowledge this is the first finding of upregulated CART in animals with deficient leptin signalling. 
Investigation of the subcellular localisation of CART using TEM and immunogold labelling on ultrathin sections revealed that anti-CART labelling in DEX rats localised to the secretory granules of both $\beta$-cells and $\delta$-cells [39]. This is a strong indication that CART is secreted from both $\beta$-cells and $\delta$-cells, and, in addition, it provides the morphological substrate for cosecretion of CART and insulin as well as CART and somatostatin.

\section{Neurons}

In addition to endocrine cells, CART is widely expressed in both nerve fibers and in nerve cell bodies in pancreatic ganglia, sometimes forming neuroislet complexes. The CART expressing neurons are particularly prominent in the mouse pancreas during development (Fig. 2A). In both rat and mouse pancreas CART is present in parasympathetic (VIPcontaining) and sensory (CGRP-containing) nerves [35; 38]. In the pancreas the parasympathetic nerves are known to activate insulin secretion [1]. Interestingly, CART is released in pigs upon vagal stimulation [32]. Hence, CART may be involved in the regulation of parasympathetic control of islet function. The finding of CART in the peripheral endings of sensory neurons further suggests a role for CART in the regulation of insulin secretion since these neurons are proposed to exert a tonic inhibition on insulin secretion [1]. Further, it has been reported that CART stimulates rat pancreatic exocrine secretion, and that the effect is reduced after blocking parasympathetic transmission with atropine and abolished after vagotomy [8]. These findings suggest an action of CART on parasympathetic nerve transmission in the pancreas. Thus, another function of CART in pancreatic nerves may be to modulate neuronally mediated exocrine pancreatic secretion. Although CART is localised to preganglionic sympathetic neurons at other sites [11], CART is absent from pancreatic sympathetic nerve fibers [35]. The data on neurotrophic properties of CART on certain neurons in vitro [23] is intriguing and a role for CART as a survival/differentiation factor for pancreatic neurons is not inconceivable. 


\section{CART in human pancreas}

Data on CART in the human pancreas are scarce. We have found CART in intrapancreatic neurons and in islet cells during fetal development (own unpublished observations). These findings are of great importance and provides anatomical prerequisites for a function of CART in the regulation of pancreatic endocrine and exocrine processes also in humans. In addition, we have found CART to colocalise with insulin in human insulinomas. Interestingly, the expression of CART seems to be related to the degree of differentiation of the tumour. Thus, highly differentiated tumours with high insulin IR also displayed high CART IR, whereas less differentiated tumours with only weak insulin IR were devoid of CART IR (Fig. 4). Hence, CART may be a marker of certain islet tumours. A potential role for CART in tumour differentiation remains to be elucidated.

\section{CART regulates islet hormone secretion}

The extensive expression of CART in the islets and in pancreatic neurons points to a role for CART in islets function. Interestingly therefore, CART regulates islet hormone secretion from clonal $\beta$-cells and from isolated rat islets. Thus, under conditions of cAMP-amplified glucose-stimulated insulin secretion (GSIS), CART acts to boost insulin secretion even further [39]. This effect could be explained by a further increase in intracellular cAMP and subsequently exaggerated activation of PKA. On the other hand, in the absence of cAMP elevating agents, i.e. with glucose alone as insulin secretagogue, CART caused decreased insulin secretion from isolated rat islets [39]. This reduction of insulin secretion could be caused by the parallel drop in glucagon, which is known to stimulate insulin secretion via cAMP. In addition, CART lowered also somatostatin secretion from isolated rat islets in the absence of cAMP elevating agents. One would expect this to result in increased GSIS; 
however, since somatostatin inhibits both insulin and glucagon, lowered somatostatin secretion does not necessarily result in increased insulin secretion.

Our hypothesis that the decreased glucagon secretion is responsible for the drop in GSIS gains support from our data on clonal $\beta$-cells. Here CART was without effect under solely glucose stimulated conditions. Together it seems that the stimulatory effect of CART on GSIS is dependent on a high intracellular cAMP level. Our finding [39] that CART increased also IBMX stimulated GSIS from clonal $\beta$-cells indicates that not only activation of adenylate cyclase by forskolin or GLP-1, but also inhibition of cAMP degradation can produce this state of high cAMP necessary for CART to boost GSIS. It also indicates that the effect of CART is not explained by modulation of cAMP breakdown. Based on the assumption that a certain level of cAMP is needed to trigger the stimulating effect of CART on GSIS one may speculate the following. When glucagon secretion is lowered, the $\beta$-cell concentration of cAMP is decreased and, thus, CART is not able to exert a stimulatory effect on GSIS. The decreased GSIS may therefore be explained by the combination of the decreased glucagon effect itself on GSIS and inability of CART to stimulate GSIS since the level of cAMP is too low. Our data indicating an inhibitory effect of CART on GSIS in the absence of cAMP elevating agents are in agreement with those of Wang et al [33]. On the other hand Colombo et al [6] reported no effect of CART on GSIS. Further, studying isolated perfused porcine pancreas, Tornoe et al [32] were unable to detect any effects of CART on insulin or glucagon secretion. There is no ready explanation for the divergent data; one explanation could be that there are CART-related species differences between rat and pig. The documented reduction in plasma insulin and leptin caused by chronic central infusion of CART in the rat [28] is intriguing and raises questions about the action of CART on the islets in intact animals. Further studies are needed to clarify the actual roles for CART on islet hormone secretion in vivo. In view of the effects of CART on GLP-1 mediated GSIS, future islet studies of possible 
effect of CART on GLP-1 stimulated $\beta$-cell proliferation and/or differentiation $[5 ; 16]$ would be of great interest. In view of successful clinical trials with GLP-1 [2; 17] the potentiating effect of CART on GLP-1 mediated GSIS is intriguing, and the potential of CART in combination wit GLP-1 in the treatment of type-2 diabetes needs further investigation.

\section{Absence of CART}

CART KO mice develop increased body weight after 40 weeks on a normal diet [38] and, in another strain of CART KO mice, at the age of 17 weeks when fed a high fat diet for 14 weeks [3]. In addition, absence of CART results in impaired GSIS and impaired glucose elimination explained by islet dysfunction. Importantly, the defect is apparent both in vivo and in isolated islets already in young CART-deficient mice with no difference in body weight from wild type mice. Although the islets in CART KO animals appear normal with respect to size, islet hormone expression and intra-islet cell topography, the $\beta$-cells have markedly reduced expression of GLUT-2 and PDX-1. GLUT-2 is a major determinant of glucose uptake in beta cells [31] whereas PDX-1 is of importance for beta cell development and insulin gene expression [19; 27]. Notably, genetic deletion of either GLUT-2 [15] or PDX-1 [19] is associated with defective insulin secretion and glucose intolerance. Thus, CART does not seem to be crucial for development of appropriate islet size or islet cell topography, but rather to the $\beta$-cell function. Although the decreased expression of PDX-1 and GLUT-2 may be secondary to the diabetic phenotype of the animals, a role for CART in maintenance of appropriate levels of these proteins cannot be ruled out. Together our data suggest that CART is necessary for maintaining normal islet function. In view of the potentiating effect of CART on cAMP mediated GSIS, studies of cAMP mediated insulin secretion in CART KO mice would be of great interest. 
It is of notice in this context that humans with a missense mutation resulting in heterozygosity for CART were reported to have, in addition to obesity, a higher incidence of type-2 diabetes [10]. Thus it seems that also humans are susceptible for alterations in CART availability and lowering the gene dose to half is enough to result in increased type-2 diabetes incidence and obesity. It is, however, not possible to tell from that report whether the type-2 diabetes is secondary to the reported obesity or is due to a defect at the islet level. Interestingly, it seems that humans are more sensitive to CART than are mice, since CART heterozygous mice did not develop obesity when fed a normal laboratory diet (own unpublished observations). However, Asnicar et al [3] showed that while after feeding a high fat diet male CART heterozygous mice were of normal weight, females had slightly increased body weight.

\section{A role for CART during development?}

Given the fact that the islets are virtually flooded by CART during development, the role for CART as a regulator of islet hormone secretion during development remains to be elucidated. If so: does the inhibitory effect on glucagon secretion, leading to decreased insulin secretion or does the stimulatory effect on GLP-1 mediated insulin secretion predominate?

During fetal and neonatal development an array of insulin inhibitors are upregulated locally in the islets. Among such inhibitors are NPY, expressed in the $\beta$-cells perinatally [24; 26], and PYY, expressed mainly in $\alpha$-cells and PP-cells during rodent ontogeny [4; 26]. It has been speculated that one function of this upregulation is to protect the fetus from hypoglycemia. This may be the function also for CART, which inhibits GSIS under basal conditions. On the other hand, CART stimulates GLP-1 mediated insulin secretion. Interestingly therefore Sjöholm et al [29] reported that although long-term GLP-1 in vitro increased insulin content in isolated fetal rat islets, GLP-1 did not affect short-term GSIS. This may indicate that the 
GLP-1-islet axis is not functioning as in the adult animal; thus the main role for CART during fetal life could be to serve as an inhibitor of insulin secretion.

\section{Concluding remarks}

CART can now be added to the array of regulatory peptides that are involved in the complex regulation of islet function, and it is now established that CART is needed for maintaining normal islet function. It is also established that CART regulates islet hormone secretion, although other functions such as influence on islet growth and maintenance cannot be ruled out. An important information still lacking is how islet CART interacts with the many other locally expressed regulatory peptides. Although it is clear that CART is upregulated in $\beta$-cells of rodent models of type-2 diabetes, a role for CART in type-2 diabetes pathophysiology needs further investigation.

\section{ACKNOWLEDGEMENTS}

Grant supports from: Swedish Medical Research Council (Project No. 4499), The Swedish Royal Physiographic Society, Novo Nordic, Goljes Minne, Tore Nilsson, Åke Wibergs, and Gyllenstiernska Krapperup Foundations.

\section{FIGURE LEGENDS}

Fig 1. Low magnification immunofluorescence photomicrographs of fetal rat pancreas (E20) double immunostained for CART (A) and insulin (B); merged in C. Scale bar $=100 \mu \mathrm{m}$. CART is expressed in all islets, predominantly in the insulin producing $\beta$-cells.

Fig 2. Neonatal mouse islets. A: Double immunostaining for CART (red) and insulin (green). CART immunoreactive cells (exemplified with big arrow-heads) are different from the 
insulin-producing $\beta$-cells. CART is highly expressed in pancreatic nerve fibers (exemplified with small arrow-heads) and ganglionic nerve cell bodies (indicates with g) within neuro islet complexes. C: Double immunostaining for CART (red) and glucagon (green). CART is expressed in a subpopulation of the glucagon-producing $\alpha$-cells (colocalisation exemplified with arrow-heads). B: Double immunostaining for CART (red) and insulin (green). D: the same section as in B after wash and immunostaining for somatostatin (red). CART immunoreactive cells are different from the somatostatin-producing $\delta$-cells. Arrowheads in D, point out the location of the indicated CART immunoreactive cells in B. Scale bar $=50 \mu \mathrm{m}$.

Fig 3. Rat islets triple-immunostained for CART (A; E), somatostatin (B; F) and insulin (C; G); merged in D and H. Upper panel: Saline treated control rats. CART is mainly localised to the somatostatin-producing $\delta$-cells. Lower panel: Dexamethasone-treated rats. CART is robustly upregulated in the insulin-producing $\beta$-cells. Scale bar $=20 \mu \mathrm{m}$.

Fig 4. Human insulin producing islet tumors double immunostained for CART (A, D) and insulin (B, E); merged in C and F. CART immunoreactivity is seen in a tumour with highly differentiated, insulin-rich cells (A-C) but not in a tumour with less differentiated cells (D-F). 


\section{REFERENCES}

[1] Ahren B: Autonomic regulation of islet hormone secretion--implications for health and disease. Diabetologia 43:393-410, 2000

[2] Ahren B, Schmitz O: GLP-1 receptor agonists and DPP-4 inhibitors in the treatment of type 2 diabetes. Horm Metab Res 36:867-876, 2004

[3] Asnicar MA, Smith DP, Yang DD, Heiman ML, Fox N, Chen YF, Hsiung HM, Koster A: Absence of cocaine- and amphetamine-regulated transcript results in obesity in mice fed a high caloric diet. Endocrinology 142:4394-4400, 2001

[4] Bottcher G, Ahren B, Lundquist I, Sundler F: Peptide YY: intrapancreatic localization and effects on insulin and glucagon secretion in the mouse. Pancreas 4:282-288, 1989

[5] Brubaker PL, Drucker DJ: Minireview: Glucagon-like peptides regulate cell proliferation and apoptosis in the pancreas, gut, and central nervous system. Endocrinology 145:26532659, 2004

[6] Colombo M, Gregersen S, Xiao J, Hermansen K: Effects of Ghrelin and Other Neuropeptides (CART, MCH, Orexin A and B, and GLP-1) on the Release of Insulin From Isolated Rat Islets. Pancreas 27:161-166, 2003

[7] Couceyro PR, Koylu EO, Kuhar MJ: Further studies on the anatomical distribution of CART by in situ hybridization. J Chem Neuroanat 12:229-241, 1997

[8] Cowles RA, Segura BJ, Mulholland MW: Stimulation of rat pancreatic exocrine secretion by cocaine- and amphetamine-regulated transcript peptide. Regul Pept 99:61-68, 2001

[9] Dall Vechia S, Lambert PD, Couceyro PC, Kuhar MJ, Smith Y: CART peptide immunoreactivity in the hypothalamus and pituitary in monkeys: analysis of ultrastructural features and synaptic connections in the paraventricular nucleus. J Comp Neurol 416:291-308, 2000

[10] del Giudice EM, Santoro N, Cirillo G, D'Urso L, Di Toro R, Perrone L: Mutational screening of the CART gene in obese children: identifying a mutation (Leu34Phe) associated with reduced resting energy expenditure and cosegregating with obesity phenotype in a large family. Diabetes 50:2157-2160, 2001

[11] Dun NJ, Dun SL, Kwok EH, Yang J, Chang J: Cocaine- and amphetamine-regulated transcript-immunoreactivity in the rat sympatho-adrenal axis. Neurosci Lett 283:97-100, 2000 [12] Ekblad E, Kuhar M, Wierup N, Sundler F: Cocaine- and Amphetamine-Regulated Transcript (CART): Distribution and function in rat gastro-intestinal tract.

Neurogastroenterology \& Motility 15:1-13, 2003

[13] Elias CF, Lee C, Kelly J, Aschkenasi C, Ahima RS, Couceyro PR, Kuhar MJ, Saper CB, Elmquist JK: Leptin activates hypothalamic CART neurons projecting to the spinal cord. Neuron 21:1375-1385, 1998

[14] Goto Y, Kakizaki M, Masaki N: Spontaneous diabetes produced by selective breeding of normal Wistar rats. Proc Jpn Acad 57:80-85, 1975

[15] Guillam MT, Hummler E, Schaerer E, Yeh JI, Birnbaum MJ, Beermann F, Schmidt A, Deriaz N, Thorens B, Wu JY: Early diabetes and abnormal postnatal pancreatic islet development in mice lacking Glut-2. Nat Genet 17:327-330, 1997

[16] Holst JJ, Orskov C: Incretin hormones--an update. Scand J Clin Lab Invest Suppl 234:7585, 2001

[17] Holst JJ, Deacon CF: Glucagon-like peptide 1 and inhibitors of dipeptidyl peptidase IV in the treatment of type 2 diabetes mellitus. Curr Opin Pharmacol 4:589-596, 2004 [18] Jensen PB, Kristensen P, Clausen JT, Judge ME, Hastrup S, Thim L, Wulff BS, Foged C, Jensen J, Holst JJ, Madsen OD: The hypothalamic satiety peptide CART is expressed in anorectic and non-anorectic pancreatic islet tumors and in the normal islet of Langerhans. FEBS Lett 447:139-143, 1999 
[19] Jonsson J, Carlsson L, Edlund T, Edlund H: Insulin-promoter-factor 1 is required for pancreas development in mice. Nature 371:606-609, 1994

[20] Koylu EO, Couceyro PR, Lambert PD, Ling NC, DeSouza EB, Kuhar MJ:

Immunohistochemical localization of novel CART peptides in rat hypothalamus, pituitary and adrenal gland. $J$ Neuroendocrinol 9:823-833, 1997

[21] Kristensen P, Judge ME, Thim L, Ribel U, Christjansen KN, Wulff BS, Clausen JT, Jensen PB, Madsen OD, Vrang N, Larsen PJ, Hastrup S: Hypothalamic CART is a new anorectic peptide regulated by leptin. Nature 393:72-76, 1998

[22] Larsson LI, Rehfeld JF, Sundler F, Hakanson R: Pancreatic gastrin in foetal and neonatal rats. Nature 262:609-610, 1976

[23] Louis JCM: Methods of preventing neuron degeneration and promoting neuron regeneration. In Amgen, International Patent Application Publication \#WO96/34619, 1996

[24] Moltz JH, McDonald JK: Neuropeptide Y: direct and indirect action on insulin secretion in the rat. Peptides 6:1155-1159, 1985

[25] Mulder H, Myrsen-Axcrona U, Gebre-Medhin S, Ekblad E, Sundler F: Expression of non-classical islet hormone-like peptides during the embryonic development of the pancreas. Microsc Res Tech 43:313-321, 1998

[26] Myrsen-Axcrona U, Ekblad E, Sundler F: Developmental expression of NPY, PYY and PP in the rat pancreas and their coexistence with islet hormones. Regul Pept 68:165-175, 1997 [27] Ohlsson H, Karlsson K, Edlund T: IPF1, a homeodomain-containing transactivator of the insulin gene. Embo J 12:4251-4259, 1993

[28] Rohner-Jeanrenaud F, Craft LS, Bridwell J, Suter TM, Tinsley FC, Smiley DL, Burkhart DR, Statnick MA, Heiman ML, Ravussin E, Caro JF: Chronic central infusion of cocaine- and amphetamine-regulated transcript (CART 55-102): effects on body weight homeostasis in lean and high-fat-fed obese rats. Int J Obes Relat Metab Disord 26:143-149, 2002 [29] Sjoholm A, Sandberg E, Ostenson CG, Efendic S: Peptidergic regulation of maturation of the stimulus-secretion coupling in fetal islet beta cells. Pancreas 20:282-289, 2000 [30] Stojanovska L, Rosella G, Proietto J: Evolution of dexamethasone-induced insulin resistance in rats. Am J Physiol 258:E748-756, 1990

[31] Thorens B: Molecular and cellular physiology of GLUT-2, a high-Km facilitated diffusion glucose transporter. Int Rev Cytol 137:209-238, 1992

[32] Tornoe K, Orskov C, Clausen JT, Thim L, Wulff BS, Holst JJ: CART (Cocaine and amphetamine regulated transcript); a new neurotransmitter in the porcine gastrointestinal tract. Gastroenterology 116:G4743 (Abstract), 1999

[33] Wang Z, Wang R, Taheri S, Ghatei M, Bloom SR. In The Enocrine Society Meeting Betsheda M, Ed. Toronto, 2000, p. 96, Abs 370

[34] Wierup N, Svensson H, Mulder H, Sundler F: The ghrelin cell: a novel developmentally regulated islet cell in the human pancreas. Regul Pept 107:63-69, 2002

[35] Wierup N, Kuhar MJ, Nilsson BO, Mulder H, Ekblad E, Sundler F: Cocaine- and amphetamine- regulated transcript (CART) is expressed in several islet cell types during rat development. J. Histochem. Cytochem. 52:169, 2004

[36] Wierup N, Yang S, McEvilly RJ, Mulder H, Sundler F: Ghrelin is expressed in a novel endocrine cell type in developing rat islets and inhibits insulin secretion from INS-1 (832/13) cells. J Histochem Cytochem 52:301-310, 2004

[37] Wierup N: Ghrelin and CART, two new islet peptides. Expression, regulation, and function. In Department of Experimental Medical Science Lund, Lund University, 2005, p. 73 [38] Wierup N, Richards WG, Bannon AW, Kuhar MJ, Ahren B, Sundler F: CART knock out mice have impaired insulin secretion and glucose intolerance, altered beta cell morphology and increased body weight. Regul Pept 129:203-211, 2005 
[39] Wierup N, Bjorkqvist M, Kuhar MJ, Mulder H, Sundler F: CART Regulates Islet Hormone Secretion and Is Expressed in the \{beta\}-Cells of Type 2 Diabetic Rats. Diabetes 55:305-311, 2006 


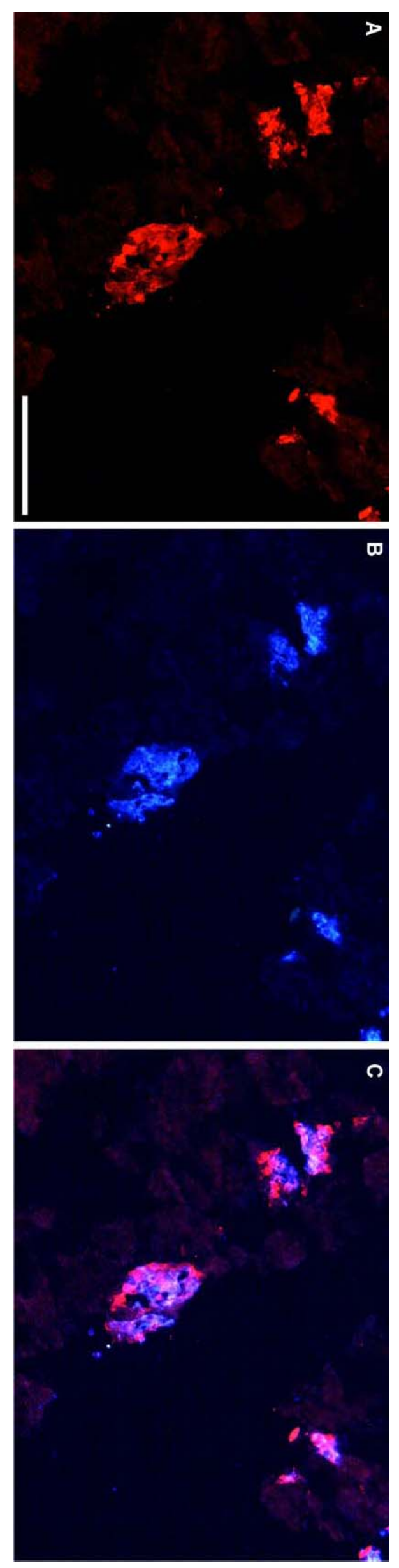




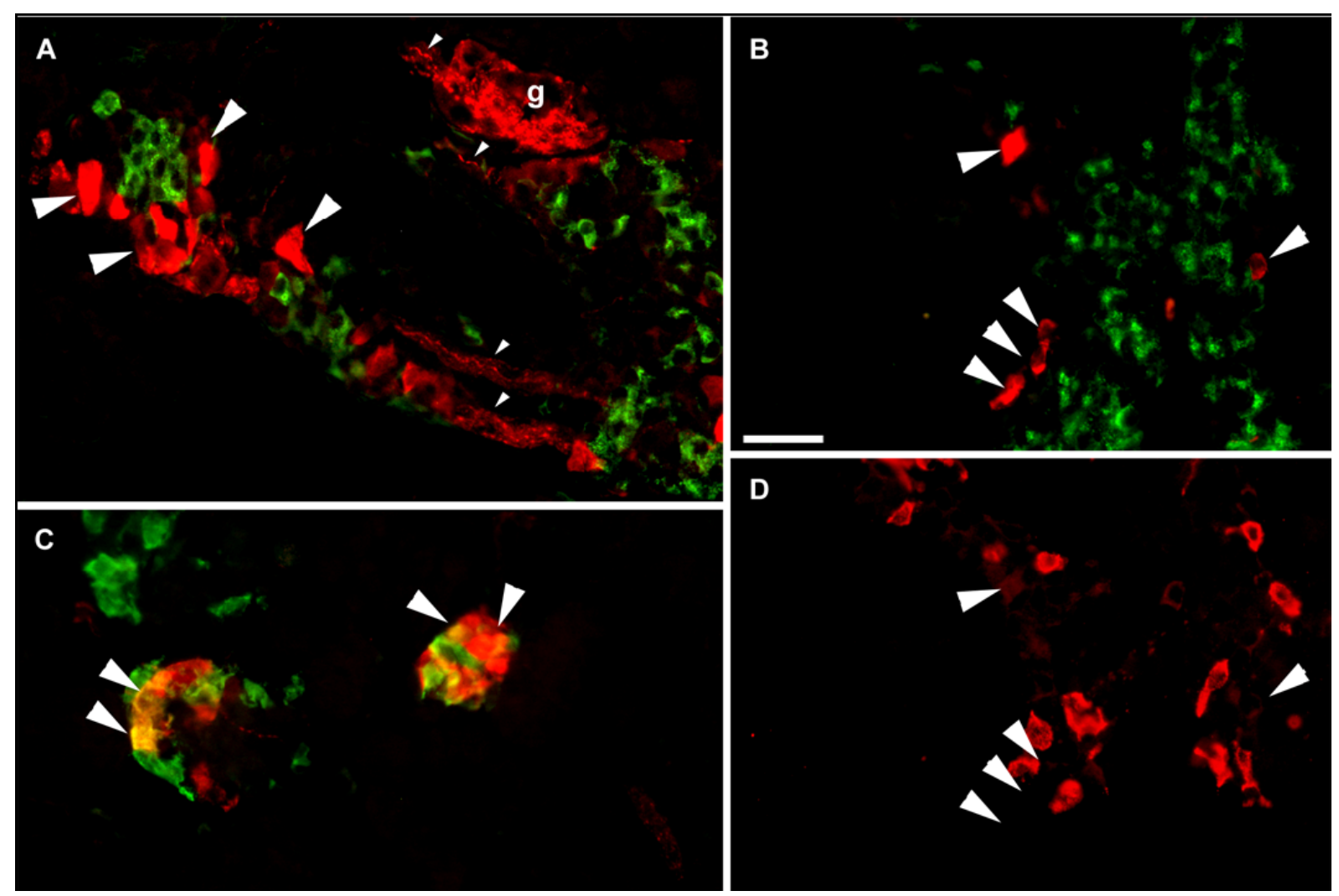




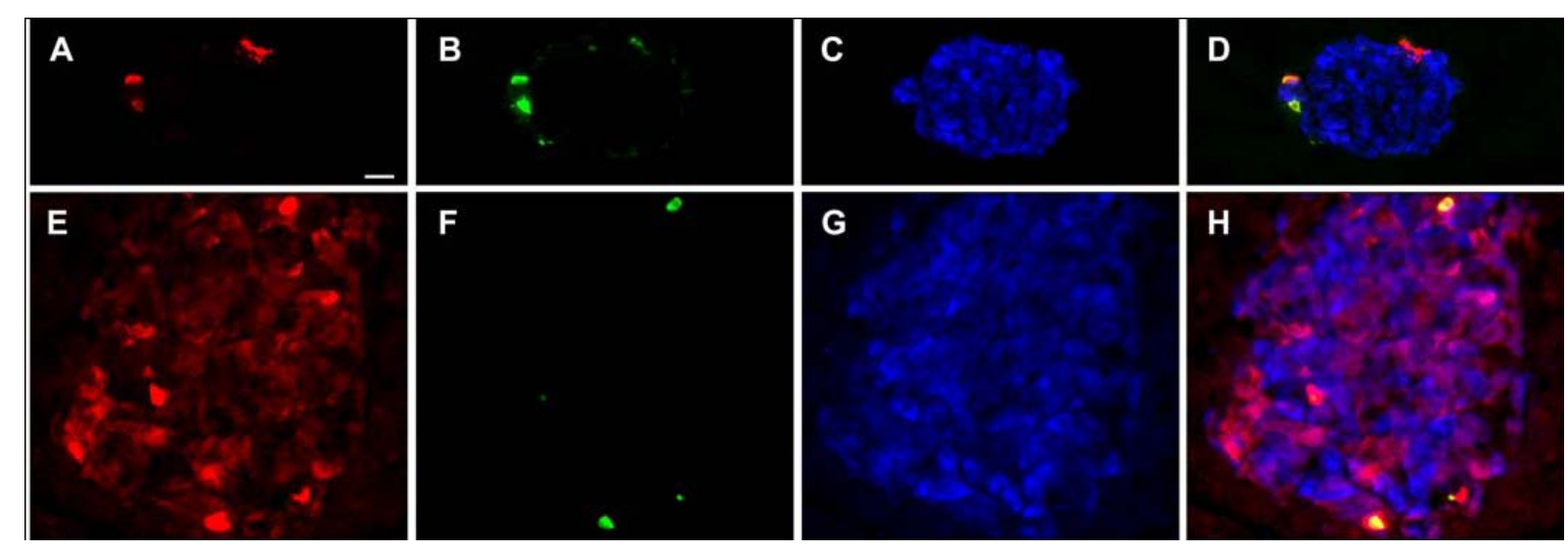




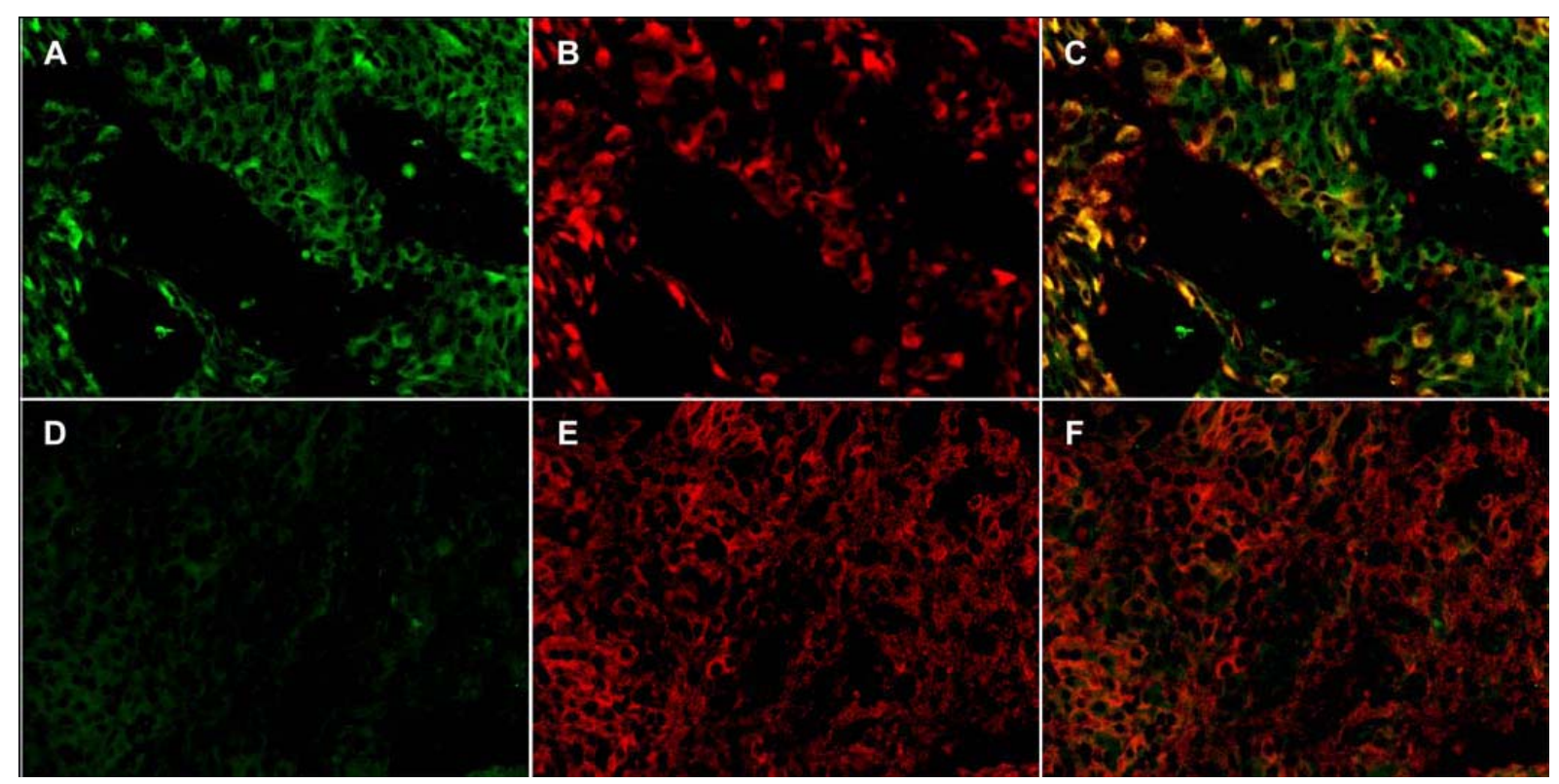

